\title{
Subsurface ocean temperature indices for Central-Pacific and Eastern-Pacific types of El Niño and La Niña events
}

\author{
Jin-Yi Yu • Hsun-Ying Kao • Tong Lee • Seon Tae Kim
}

Received: 25 January 2010 / Accepted: 12 June 2010 /Published online: 22 June 2010

(C) The Author(s) 2010. This article is published with open access at Springerlink.com

\begin{abstract}
Subsurface ocean temperature indices are developed to identify two distinct types of tropical Pacific warming (El Niño) and cooling (La Niña) events: the Eastern-Pacific (EP) type and the Central-Pacific (CP) type. Ocean temperature anomalies in the upper $100 \mathrm{~m}$ are averaged over the eastern $\left(80^{\circ} \mathrm{W}-90^{\circ} \mathrm{W}, 5^{\circ} \mathrm{S}-5^{\circ} \mathrm{N}\right)$ and central $\left(160^{\circ} \mathrm{E}-150^{\circ} \mathrm{W}, 5^{\circ} \mathrm{S}-5^{\circ} \mathrm{N}\right)$ equatorial Pacific to construct the EP and $\mathrm{CP}$ subsurface indices, respectively. The analysis is performed for the period of 1958-2001 using an ocean data assimilation product. It is found that the $\mathrm{EP} / \mathrm{CP}$ subsurface indices are less correlated and show stronger skewness than the sea surface temperature (SST)based indices. In addition, while both quasi-biennial ( $\sim 2$ years) and quasi-quadrennial ( $\sim 4$ years) periodicities appear in the SST-based indices for these two types, the subsurface indices are dominated only by the quasi-biennial periodicity for the CP type and by the quasi-quadrennial ( 4 years) periodicity for the EP type. Low correlation, high skewness, and single leading periodicity are desirable properties for defining indices to separate the EP and $\mathrm{CP}$ types. Using the subsurface indices, major El Niño and La Niña events identified by the Niño-3.4 SST index are classified as the EP or CP types for the analysis period. It is found that most strong El Niño events are of the EP type
\end{abstract}

J.-Y. Yu $(\bowtie) \cdot$ S. T. Kim

Department of Earth System Science, University of California, Irvine, CA 92697-3100, USA

e-mail: jyyu@uci.edu

H.-Y. Kao

Earth and Space Research,

Seattle, WA, USA

T. Lee

Jet Propulsion Laboratory, California Institute of Technology,

Pasadena, CA, USA while most strong La Niña events are of the CP type. It is also found that strong CP-type La Niña events tend to occur after strong EP-type El Niño events. The reversed subsequence (i.e., strong EP El Niño events follow strong CP La Niña events) does not appear to be typical. This study shows that subsurface ocean indices are an effective way to identify the EP and CP types of Pacific El Niño and La Niña events.

\section{Introduction}

Recent studies have begun to suggest that there are two distinct types of interannual tropical Pacific warming and cooling events that are often referred to as El Niño and La Niña, respectively. The conventional type of El Niño/La Niña events is similar to tropical Pacific sea surface temperature (SST) variations described by Rasmusson and Carpenter (1982) which tend to have their anomaly center located in the eastern Pacific. The other type of El Niño/La Niña events has their SST anomaly center located in the central Pacific. Kao and Yu (2009) refer these two types of tropical Pacific SST variations as the Eastern-Pacific (EP) and the Central-Pacific (CP) types. Different terms were also used to describe the CP type of warming, including "Dateline El Niño" (Larkin and Harrison 2005), "El Niño Modoki" (Ashok et al. 2007), and "Warm pool El Niño" (Kug et al. 2009). Kao and Yu (2009) analyzed reanalysis and assimilation datasets to show that the EP type is associated with basin-wide atmosphere-ocean coupling processes similar to those described by the delayed oscillator theory (Battisti and Hirst 1989; Suarez and Schopf 1988) while the CP type is associated with local coupling processes in the central Pacific. Yu et al. (2009) conducted numerical experiments with the National Center for Atmospheric Research (NCAR) Community Climate 
System Model version 3.0 (CCSM3.0) to show that atmospheric forcing from Asian-Australian monsoon variations is able to excite the CP type. Yu et al. (2010) further conducted surface ocean heat budget analysis to show that forcing from the northeastern subtropical sea level pressure (SLP) variations can also excite the CP-type events via surface heat flux and wind-induced ocean advections. This series of modeling and observational studies have lead to the suggestion that the CP and EP types of El Niño/La Niña should be treated and monitored separately.

In the above-mentioned recent studies, the $\mathrm{CP}$ and $\mathrm{EP}$ events were identified with different methods but were all based on tropical Pacific SST anomalies. For example, Ashok et al. (2007) emphasized the out-of-phase relation between the SST anomalies in the central equatorial Pacific and those in the eastern and western Pacific to identify their Modoki El Niño events. Kug et al. (2009) simply compared the relative strength of the Niño-3 and Niño-4 SST anomalies to determine if an event should be considered a CP type or an EP type. Kao and Yu (2009) recognized that SST anomalies of the two types can spread and overlap over the eastern-to-central tropical Pacific and it is difficult to identify these two types based directly on the SST anomalies. They, therefore, used a combined regression-empirical orthogonal function (EOF) method to identify the EP and CP events. They first removed the tropical Pacific SST anomalies that were regressed with the Niño-4 SST index and then applied the EOF to the residual SST anomalies to obtain the SST anomaly pattern for the EP type. The principal component of this leading EOF was then used to identify the EP-type events. Similarly, the SST anomaly pattern for the CP type was obtained by applying the EOF to the residual SST anomalies after the anomalies regressed on the Niño- $1+2$ SST index were removed. The principal component of that leading EOF was used to identify the CP-type events.

Kao and Yu (2009) showed that these principal components were useful in identifying these two types of warming and cooling events. However, the calculation involved in these SST-based indices is less straightforward and also it is not easy to apply the indices directly for monitoring the EP and CP events. Kao and Yu (2009) found that the patterns of the subsurface ocean temperature anomalies associated with the EP and CP types are different. This property leads us to consider that indices based on subsurface ocean temperature anomalies may be useful in identifying and separating these two types. In this study, we develop two subsurface indices to explore this possibility.

\section{Data}

For SST information, we use the Met Office Hadley Centre Sea Ice and Sea Surface Temperature dataset (HadISST,
Rayner et al. 2003). For subsurface ocean temperature information, we use the dataset taken from the Simple Ocean Data Assimilation Reanalysis (SODA, Carton et al. 2000). We choose to analyze the period of 1958-2001, during which both the HadISST and SODA are available. Anomalous quantities are computed by removing the monthly mean climatology and the trend.

\section{Comparisons of subsurface indices and SST-based indices}

The structures of the subsurface ocean temperature anomalies associated with the EP and CP types of El Niño/La Niña are shown in Fig. 1. The values shown are the correlation coefficients between the principal components of the leading EOFs obtained by Kao and Yu (2009, as in their Fig. 3) for these two types and the upper 300-m ocean temperature anomalies averaged between $5^{\circ} \mathrm{S}$ and $5^{\circ} \mathrm{N}$ in the Pacific. For the EP type (Fig. 1a), large and out-ofphase subsurface temperature anomalies appear on both sides of the Pacific Ocean and propagate eastward along the thermocline during the evolution of the event. In contrast, the subsurface evolution of the CP type (Fig. 1b) does not have a basin-wide fluctuation pattern and neither does it show an obvious propagation feature. The initiation, development, and termination of the subsurface anomalies occur mostly in the central Pacific. The temperature anomalies start from the surface and extend downward to a shallow layer of about $100 \mathrm{~m}$. This depth is above the local thermocline, which is about $150-200-\mathrm{m}$ deep (not shown), indicating that thermocline variations are not involved in the evolution of the $\mathrm{CP}$ events. Readers are referred to Kao and $\mathrm{Yu}$ (2009) for more discussions of the subsurface SST evolutions associated with these two types.

It is noticed from Fig. 1a that the subsurface temperature anomalies associated with the EP type has a nodal point located in the central Pacific. It is the region where the $\mathrm{CP}$ type produces the largest subsurface temperature anomalies. As such, the associated subsurface temperature anomalies show a smaller spatial overlapping between these two types of events than the associated SST anomaly field (see Fig. 7 of $\mathrm{Kao}$ and $\mathrm{Yu}$ 2009). This property suggests that subsurface ocean temperature indices may be more capable of separating these two types of El Niño/La Niña events than SST-based indices.

Based on the subsurface structures shown in Fig. 1, we choose to average the upper $100-\mathrm{m}$ ocean temperature anomalies in the eastern $\left(80^{\circ} \mathrm{W}-90^{\circ} \mathrm{W}, 5^{\circ} \mathrm{S}-5^{\circ} \mathrm{N}\right)$ and central $\left(160^{\circ} \mathrm{E}-150^{\circ} \mathrm{W}, 5^{\circ} \mathrm{S}-5^{\circ} \mathrm{N}\right)$ equatorial Pacific, respectively, as the subsurface indices for the EP and CP types of El Niño/La Niña events. These two regions are indicated in Fig. 1a and b, respectively, by red-colored 
(a) EP Type

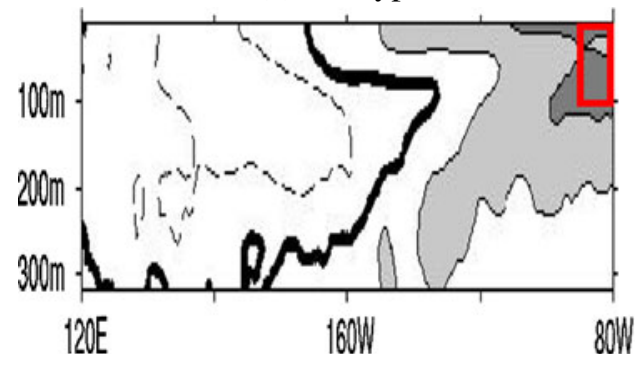

Fig. 1 Simultaneous correlation coefficients between the principal components of the leading EOF for the a EP-Type and b CP-Type events from Kao and $\mathrm{Yu}(2009)$ and the subsurface ocean temperature

boxes. The boxes show that the selected $100-\mathrm{m}$ depth is able to cover major subsurface ocean temperature anomalies for the both types. At the same time, the depth is deep enough to include the thermocline in the eastern equatorial Pacific but shallow enough not to include the thermocline in the central equatorial Pacific. Therefore, the cross-basin thermocline variations associated with the EP type is less likely to contaminate the subsurface index for the CP type.

Figure 2 shows the time series of the EP and CP subsurface indices for the period of 1958-2001 after normalization by their own standard deviations. A 3month-running smoothing was also applied. The skewness coefficient of the time series is 1.68 for the EP subsurface index and -0.63 for the $\mathrm{CP}$ subsurface index. A larger value of positive (negative) skewness denotes more extreme warm (cold) events. The skewness coefficients indicate the preference of the EP type for strong El Niño events and the CP type for strong La Niña events. It should be noted that (b) CP Type

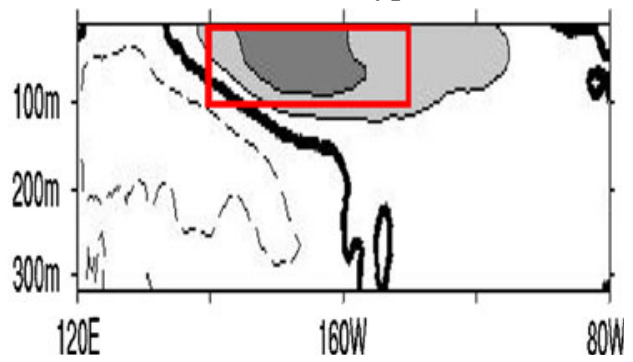

anomalies averaged between $5^{\circ} \mathrm{S}$ and $5^{\circ} \mathrm{N}$. Contour intervals are 0.3 . The red boxes denote the regions where the EP and CP subsurface indices are calculated

the skewness coefficients for the principal components of the leading EOFs of SST obtained in Kao and Yu (2009) are 1.18 and -0.45 for the EP and CP types, respectively. The spatial asymmetry between strong El Niño and strong La Niña appears more obviously revealed by the subsurface indices than by the SST-based indices (i.e., the principal components). We find that most strong El Niño events defined by the Niño-3.4 SST index are identifiable by the EP subsurface index in Fig. 2a, including the 1972/73, 1976/77, 1982/83, 1991/92, and 1997/98 events. On the other hand, most strong La Niña events defined by the Niño-3.4 SST index are identifiable by the CP subsurface index shown in Fig. 2b, including the 1973/74, 1975/76, 1983/84, 1988/89, and 1998/99 events. The correlation coefficient between the EP and CP subsurface indices is 0.27 , which is smaller than the correlation coefficient $(-0.48)$ between the two principal components of the EP and CP types. Our analyses indicate that the subsurface
Fig. 2 Time series of the normalized a EP and $\mathbf{b} \mathrm{CP}$ subsurface index. The dashed lines denote \pm 1 standard deviation (a) Time Series of EP Subsurface Index

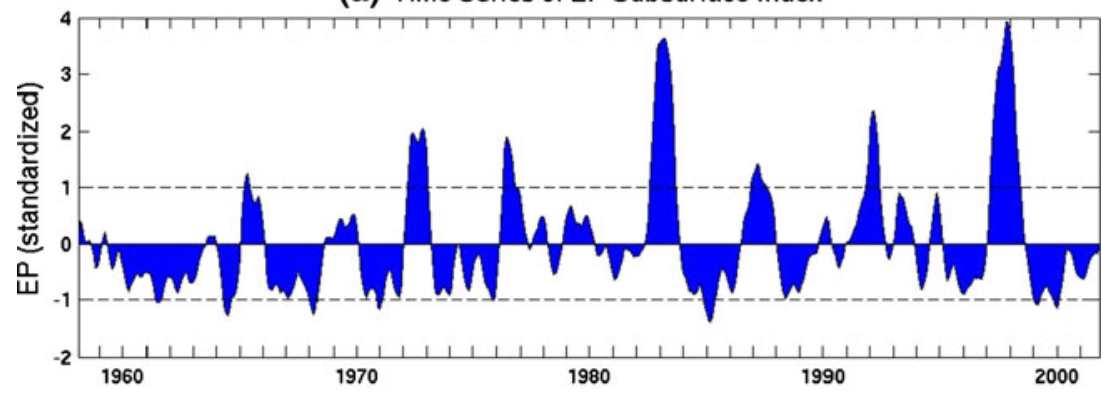

(b) Time Series of CP Subsurface Index

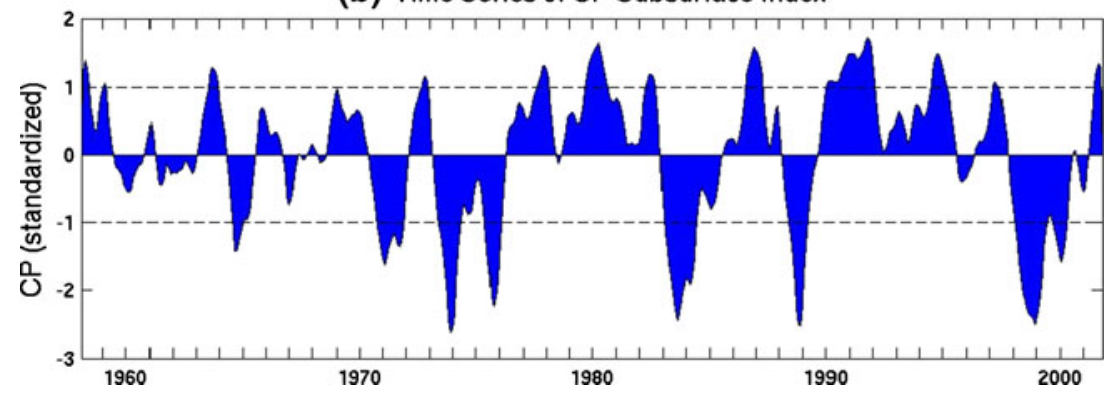


indices are more independent from each other and show stronger skewness than the SST-based indices, both of which are desirable properties for separating the EP and $\mathrm{CP}$ types.

Another interesting thing to note is that $\mathrm{Kao}$ and $\mathrm{Yu}$ (2009) found that the principal component for the EP type is dominated by a quasi-quadrennial ( $\sim 4$ years) band and a quasi-biennial ( $\sim 2$ years) band while the principal component for the CP type is dominated by a quasi-biennial band. We find that this periodicity contrast is further amplified in the subsurface indices as shown in Fig. 3 where the power spectra of the two subsurface indices are displayed. The EP subsurface index (Fig. 3a) is found to have only one significant power peak near the quasi-quadrennial band while the CP subsurface index (Fig. 3b) has a significant peak near the quasi-biennial band. The reason for this larger periodicity contrast is not known yet but the stronger contrast suggests that the subsurface indices have the potential to be more useful in separating the signals of the EP and CP types than the SST-based indices.

\section{Identification of the EP and CP types of El Niño/La Niña events using the subsurface indices}

We now link the El Niño/La Niña events identified by the Niño-3.4 SST index to the EP and CP subsurface indices. Figure 4 shows the scatter of the normalized monthly values of the EP and CP subsurface indices from 1958 to 2001. The size of every dot is proportional to the value of Niño-3.4 SST index in the corresponding month, indicating

(a) EP Type

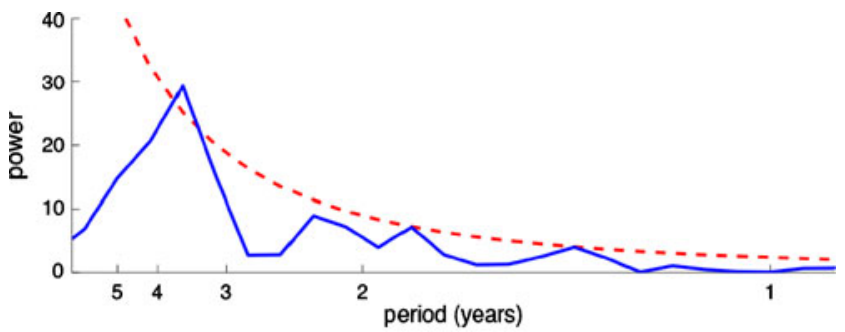

(b) CP Type

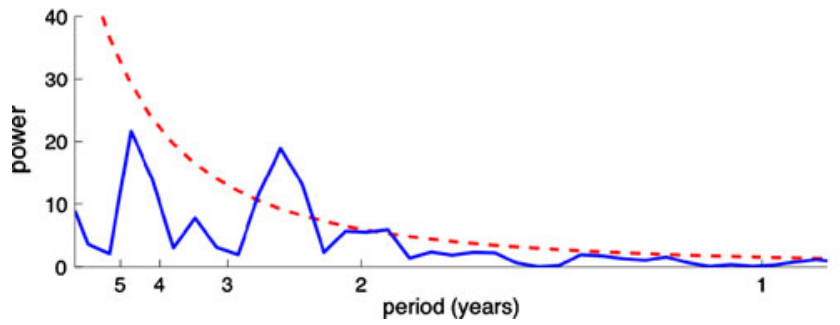

Fig. 3 Power spectrum of the normalized subsurface index for a EPand b CP-type events. The red curve represents the $99 \%$ significance level

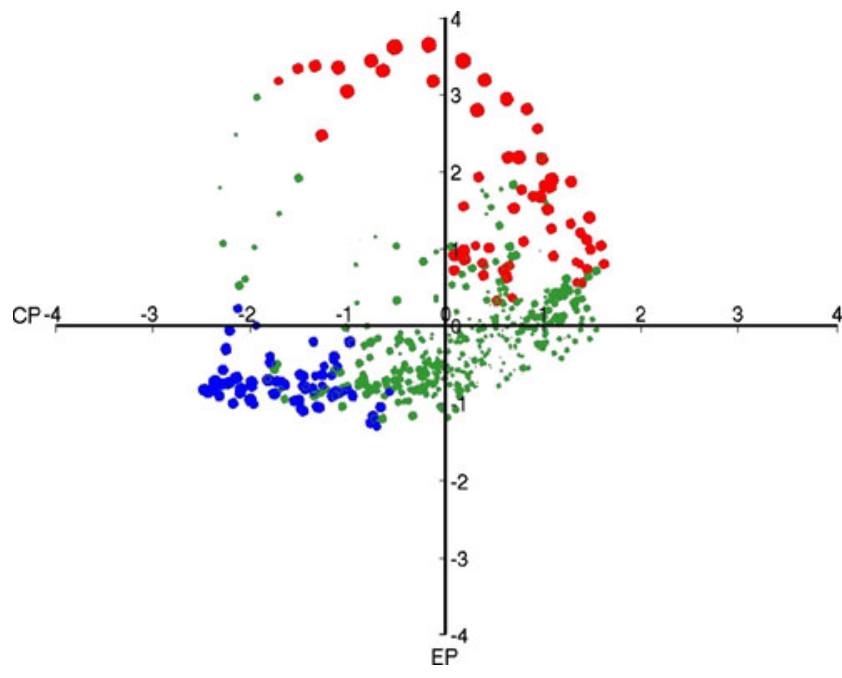

Fig. 4 Scatter plot of standardized monthly values of the EP and CP subsurface indices from 1958 to 2001. The dot size is proportional to the value of Niño-3.4 SST index in the corresponding month. The coordinate is the value of EP subsurface index. The abscissa is the value of the CP subsurface index. The dot is colored in red if its Niño3.4 SST index is larger than $1^{\circ} \mathrm{C}$, blue if the SST index is smaller than $-1^{\circ} \mathrm{C}$ and green if the SST index is between $-1^{\circ} \mathrm{C}$ and $1^{\circ} \mathrm{C}$

the strength of the event. We use this figure to examine how different strengths of El Niño/La Niña events (measured by Niño-3.4 SST index) are projected onto the EP or CP types. The dots are colored in red for large El Niño events (with the Niño-3.4 SST index larger than $1^{\circ} \mathrm{C}$ ) and blue for large La Niña events (with the Niño-3.4 SST index smaller than $-1{ }^{\circ} \mathrm{C}$ ). Here, the $\pm 1^{\circ} \mathrm{C}$ value is subjectively chosen to highlight the relatively large events. It is easy to notice from the figure that almost all the large La Niña events are projected onto the coordinate of $\mathrm{CP}$ subsurface index, with the subsurface index value changes approximately in proportion to the Niño-3.4 SST index value. For these events, the EP subsurface index values are, in general, small. This feature confirms again that strong La Niña events tend to appear as the CP type. A similar tendency can be found for the large El Niño events. A large portion of the red dots is projected onto the coordinate of EP subsurface index with smaller CP subsurface index values, indicating strong El Niño events tend to appear as the EP type.

We next develop criteria to use the subsurface indices to identify EP and CP types of El Niño/La Niña events. During the analysis period of 1958-2001, the National Oceanic and Atmospheric Administration (NOAA) has identified twelve El Niño events and ten La Niña events based on the 3-month-running mean of Niño 3.4 SST index that is termed Oceanic Niño Index (ONI). These events are listed in Table 1. To be considered as an El Niño event by NOAA, the ONI value has to be larger than $0.5^{\circ} \mathrm{C}$ for five consecutive months. We find that if we want to use the 
subsurface indices to identify all these events, the absolute values of the $\mathrm{EP} / \mathrm{CP}$ subsurface index have to be greater than 0.5 standard deviation. The standard deviation is $1.3^{\circ} \mathrm{C}$ for the EP subsurface index and $0.55^{\circ} \mathrm{C}$ for the $\mathrm{CP}$ subsurface index.

Using this criterion, we are able to classify each of the ONI-identified events into the EP or CP types as indicated in Table 1. The table shows that, in many cases, both the EP and CP types occurred for the duration of the ONIidentified El Niño/La Niña events. For example, 1982/83 sees a weak CP-type El Niño and a strong EP-type El Niño occurred in the tropical Pacific, rather than just a single warming event. Upon a closer inspection of the SST evolution (Fig. 5), it is noticeable that a weak warming appeared first in the central Pacific on March 1982 and reached to its peak intensity (about $+1{ }^{\circ} \mathrm{C}$ ) on June 1982 (Fig. 5a-d). A second warming emerged near the South American coast on July 1982 which eventually developed into one of the strongest El Niño events of the twentieth century (Fig. 5e-j). According to the central location of the SST anomalies and their subsequent evolution, the first weak warming is a CP type and the second strong warming is an EP type. Therefore, the well-known 1982/83 El Niño is actually a combination of two warming events.

We further sort the identified ONI events according to their strengths. An event is considered a strong one if the absolute value of its subsurface index is larger than two standard deviations, otherwise the event is considered a weak one. Table 2 summarizes all the strong and weak EP and CP events for the period of 1958-2001 based on this criterion. The table shows that all the strong El Niño events are the EP type while most of the weak El Niño events are

Table 1 Classification of the NOAA-identified El Niño and La Niña events into the EP or CP types according to the subsurface ocean indices

\begin{tabular}{lrllrl}
\hline \multicolumn{1}{l}{ El Niño } & Types & & \multicolumn{1}{l}{ La Niña } & Types \\
\hline 1 & $7 / 63-1 / 64$ & $\mathrm{CP}$ & 1 & $4 / 64-2 / 65$ & $\mathrm{EP} / \mathrm{CP}$ \\
2 & $6 / 65-4 / 66$ & $\mathrm{EP} / \mathrm{CP}$ & 2 & $12 / 67-4 / 68$ & $\mathrm{EP}$ \\
3 & $11 / 68-6 / 69$ & $\mathrm{CP}$ & 3 & $7 / 70-1 / 72$ & $\mathrm{EP} / \mathrm{CP}$ \\
4 & $9 / 69-1 / 70$ & $\mathrm{CP}$ & 4 & $5 / 73-7 / 74$ & $\mathrm{EP} / \mathrm{CP}$ \\
5 & $5 / 72-3 / 73$ & $\mathrm{EP} / \mathrm{CP}$ & 5 & $9 / 74-5 / 76$ & $\mathrm{EP} / \mathrm{CP}$ \\
6 & $9 / 76-2 / 77$ & $\mathrm{EP} / \mathrm{CP}$ & 6 & $10 / 84-9 / 85$ & $\mathrm{EP} / \mathrm{CP}$ \\
7 & $9 / 77-2 / 78$ & $\mathrm{CP}$ & 7 & $5 / 88-5 / 89$ & $\mathrm{EP} / \mathrm{CP}$ \\
8 & $5 / 82-6 / 83$ & $\mathrm{EP} / \mathrm{CP}$ & 8 & $9 / 95-3 / 96$ & $\mathrm{EP}$ \\
9 & $9 / 86-2 / 88$ & $\mathrm{EP} / \mathrm{CP}$ & 9 & $7 / 98-6 / 00$ & $\mathrm{EP} / \mathrm{CP}$ \\
10 & $5 / 91-7 / 92$ & $\mathrm{EP} / \mathrm{CP}$ & 10 & $10 / 00-2 / 01$ & $\mathrm{EP}$ \\
11 & $7 / / 94-3 / 95$ & $\mathrm{EP} / \mathrm{CP}$ & & & \\
12 & $5 / 97-4 / 98$ & $\mathrm{EP}$ & & & \\
\hline
\end{tabular}

The duration of the events is denoted in month per year the CP type. On the other hand, all strong La Niña events are the CP type while relatively weak La Niña events tend to be the EP type. The spatial asymmetry between El Niño and La Niña events is apparently reversed between strong and weak events. This is consistent with the finding reported recently by Sun and Yu (2009) in which they analyzed the decadal modulation of El Niño/La Niña SST intensity for the period of 1880-2006 and noted a similar reversal of the spatial asymmetry between El Niño and La Niña SST anomalies. In the enhanced intensity periods of the decadal modulation cycle, strong El Niño is located in the eastern tropical Pacific and strong La Niña in the central tropical Pacific. The asymmetry is reversed in the weakened intensity periods: weak El Niño centers in the central Pacific and weak La Niña in the eastern Pacific. They argued that this reversal of El Niño-La Niña asymmetry is important for giving rise to a 10-15-year modulation cycle of El Niño/La Niña intensity.

Based on the events identified in Table 2, we construct composite lifecycle for the strong EP and CP events. The lifecycle is composited according to the month of the peak intensity (measured by the subsurface index) of the identified events. During the composite analysis, we notice that a strong CP-type La Niña often follows a strong EPtype El Niño. This tendency can be identified from Table 2. For instance, the strong CP-type La Niña events of 1973/ 74, 1983/84, and 1998/99 came after the strong EP-type El Niño events of 1972/73, 1982/83, and 1997/98, respectively. The composite lifecycle of SST anomalies is shown in Fig. 6. For a strong EP-type El Niño event (Fig. 6a), SST anomalies concentrate in the eastern Pacific. About 6 to 18 months after the warming peaks, negative SST anomalies appear in the central Pacific and develop into a CP-type of La Niña event. For strong CP-type of El Niño event (Fig. 6b), the negative SST anomalies start from the central Pacific between $160^{\circ} \mathrm{E}$ and $120^{\circ} \mathrm{W}$. The event develops and decays in the central Pacific without an evident propagation. About a year before the La Niña event, there is an EP type of El Niño event. The composite shown in Fig. 6 further confirms the tendency for strong EP-type El Niño and CP-type La Niña events to occur subsequently. The possible reason for this tendency is discussed by $\mathrm{Yu}$ and Kim (2010). They performed EOF analysis of SLP variation in the extratropical Pacific and found that the second leading EOF mode can excite the CP type of El Niño and La Niña. They further noticed that this extratropical SLP mode can be excited by the EP type of El Niño and La Niña. Therefore, some CP events can be excited after the demise of the EP events through the second EOF mode of extratropical SLP variations. They suggested that this extratropical linking mechanism is the reason why a strong CP type of La Niña event tends to occur after a strong EP-type El Niño event. 
Fig. 5 Evolution of the Pacific SST anomalies for the 1982/83 El Niño event. Zero contour lines are neglected, and the shaded regions denote positive SST anomalies. Contour interval is $0.5^{\circ} \mathrm{C}$
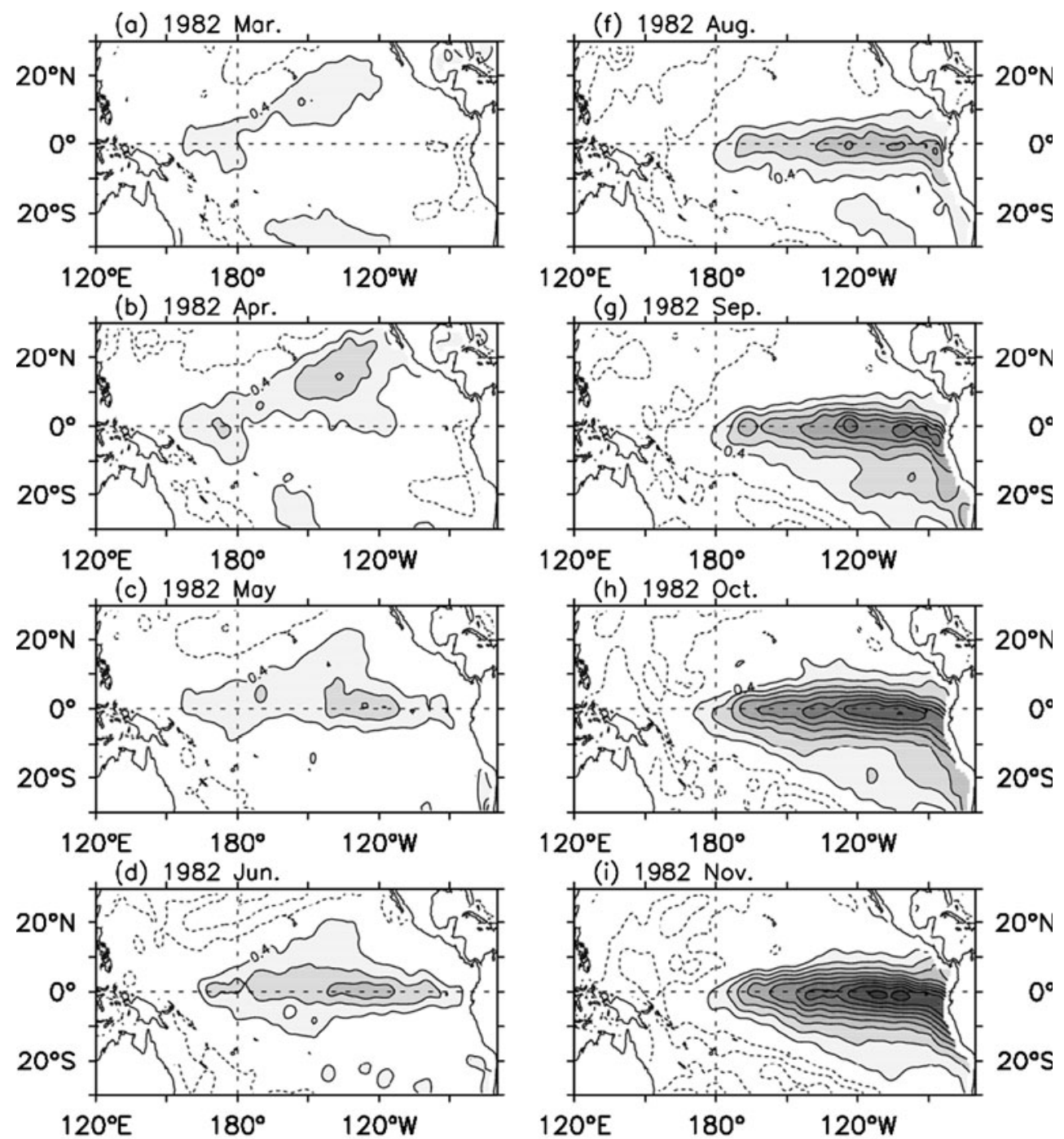

(h) 1982 Oct.
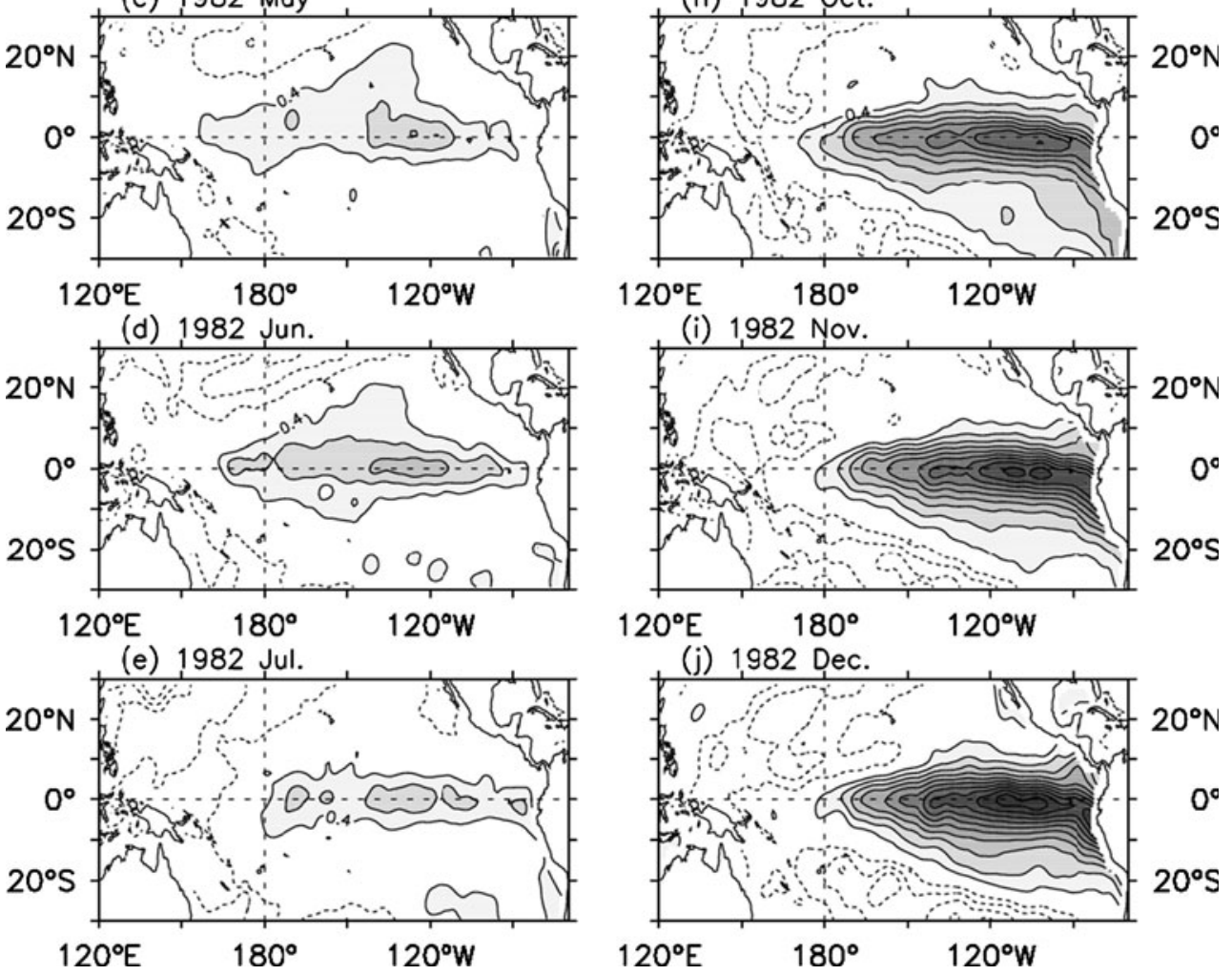

Table 2 Classification of NOAA-defined El Niño and La Niña events into strong and weak EP/CP events based on the EP and CP subsurface indices during 1958-2001

\begin{tabular}{lll}
\hline & EP & CP \\
\hline Strong El Niño & $72-73,82-83,91-92,97-98$ & None \\
Weak El Niño & $65-66,76-77,86-87,87-88,94-95$ & $63-64,65-66,68-69,69-70,72-73,76-77,77-78$, \\
& & $82-83,86-87,87-88,91-92,94-95$ \\
Strong La Niña & None & $73-74,75-76,88-89,98-99$ \\
Weak La Niña & $64-65,67-68,70-71,71-72,73-74,74-75,75-76$, & $64-65,70-71,71-72,74-75,84-85,99-00$ \\
& $84-85,88-89,95-96,98-99,99-00,00-01$ & \\
\hline
\end{tabular}


Fig. 6 Composite lifecycle of SST anomalies along the equatorial Pacific for a strong EP type of El Niño events and $\mathbf{b}$ strong CP type of La Niña events. The center month of the composite is the month of peak value of the subsurface index. Contour intervals are $0.4^{\circ} \mathrm{C}$. The right panels show the corresponding EP subsurface index (blue), CP subsurface index (red), and Niño-3.4 SST index (black) (a) Composite of strong EP-type of El Niño

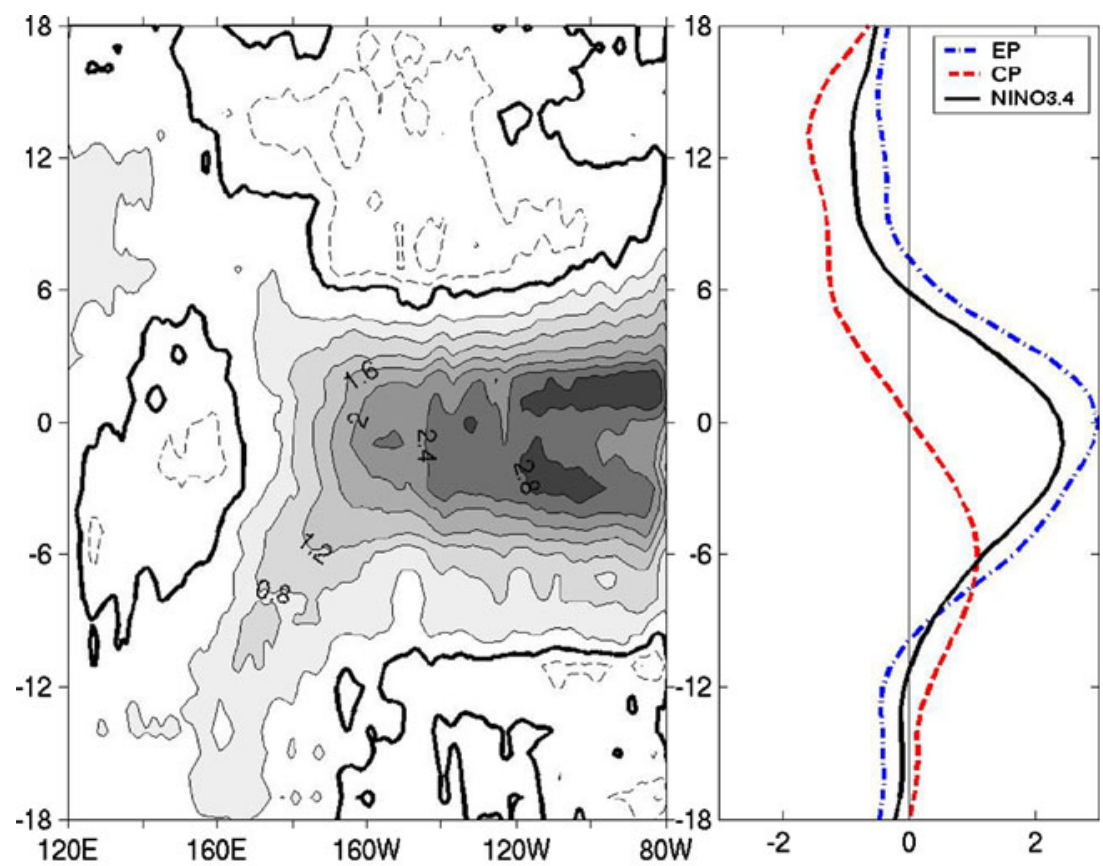

(b) Composite of strong CP-type of La Niña events

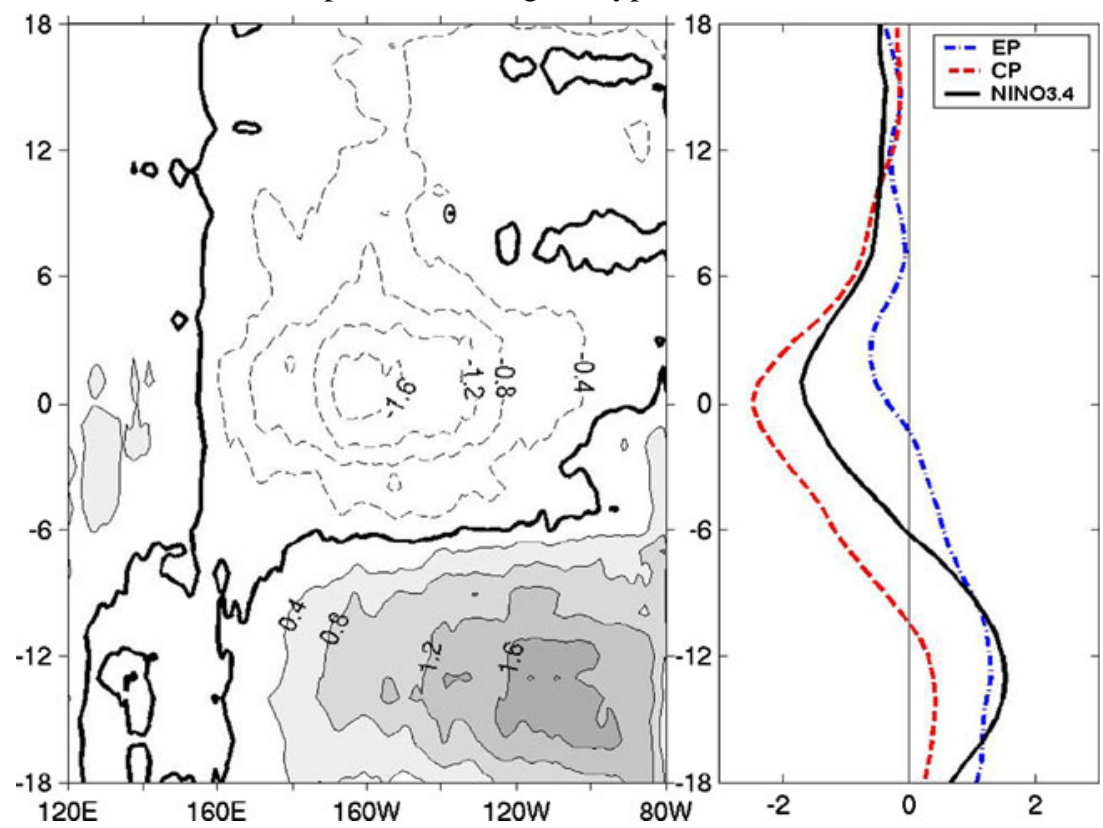

The right panels in Fig. 6 display the normalized values of the EP and CP subsurface indices and Niño-3.4 SST index during the lifecycles of the equatorial Pacific Ocean SST variations. They show that the EP subsurface index captures the evolution of El Niño events better while the CP subsurface index captures the evolution of La Niña events better than the Niño-3.4 index. The Niño-3.4 index generally has a value between the EP and CP indices. The results support the suggestion that one single index is not enough to fully capture the various types of SST variation events in the tropical Pacific (Trenberth and Stepaniak 2001). The results also indicate that the subsurface ocean temperature indices are effective in capturing the warm and cooling events in the tropical Pacific Ocean.

\section{Conclusion and discussion}

In this study, we explored the possibility of using subsurface ocean temperature indices to identify the EP 
and CP types of El Niño/La Niña events. Since the EP type is associated with basin-wide thermocline variations and the $\mathrm{CP}$ type has its subsurface temperature anomalies confined to a shallow layer in the central Pacific, subsurface indices based on temperature anomalies in the upper $100 \mathrm{~m}$ of the tropical Pacific were defined to identify these two types for the period of 1958-2001. Our analyses focused on linking the El Niño/La Niña events identified by NOAA's ONI index to the EP and CP types using the subsurface indices. It should be noted that the subsurface indices also identify some events that the SST index fails to capture. For example, in May 1966 (not shown here), positive SST anomalies appear in the eastern equatorial Pacific but was not captured by the Niño-3.4 index. However, the EP subsurface index captures the heat content variations near the coastal region during this event. Also in January 1991, the Niño-3.4 index did not capture the warming in the central Pacific, west to the Niño-3.4 region, but the CP subsurface index is able to reveal this Central-Pacific event. The criterion used in this study for the event identification is subjective and not necessary the optimal one. When more understandings are obtained on the linkages between the subsurface evolutions of the EP/CP type events and their underlying physics, further refinements can be made on the subsurface indices to increase their usefulness in monitoring, understanding, and potentially predicting the EP and CP types of El Niño/La Niña events.

Acknowledgments We thank three anonymous reviewers for their helpful comments. The research was supported by the NSF (ATM-0925396), NASA (NNX06AF49H), and JPL (subcontract No.1290687).

Open Access This article is distributed under the terms of the Creative Commons Attribution Noncommercial License which permits any noncommercial use, distribution, and reproduction in any medium, provided the original author(s) and source are credited.

\section{References}

Ashok K, Behera S, Rao AS, Weng H, Yamagata T (2007) El Niño Modoki and its teleconnection. J Geophys Res 112:C11007. doi:10.1029/2006JC003798

Battisti DS, Hirst AC (1989) Interannual variability in a tropical atmosphere-ocean model: influence of the basic state, ocean geometry and nonlinearity. J Atmos Sci 46:1687-1712

Carton JA, Chepurin GA, Cao X, Giese BS (2000) A simple ocean data assimilation analysis of the global upper ocean 1950-1995, part I: methodology. J Phys Oceanogr 30:294309

Kao H-Y, Yu J-Y (2009) Contrasting Eastern-Pacific and CentralPacific types of El Niño. J Climate 22:615-632

Kug J-S, Jin F-F, An S-I (2009) Two types of El Niño events: cold tongue El Niño and warm pool El Niño. J Climate 22:14991515

Larkin NK, Harrison DE (2005) On the definition of El Niño and associated seasonal average U.S. weather anomalies. Geophys Res Lett 32:L13705. doi:10.1029/2005GL022738

Rasmusson EM, Carpenter TH (1982) Variations in tropical sea surface temperature and surface wind fields associated with the Southern Oscillation El-Niño. Mon Wea Rev 110:354 384

Rayner NA, Parker DE, Horton EB, Folland CK, Alexander LV, Rowell DP, Kent EC, Kaplan A (2003) Global analyses of sea surface temperature, sea ice, and night marine air temperature since the late nineteenth century. J Geophys Res 108:4407. doi:10.1029/2002JD002670

Suarez MJ, Schopf PS (1988) A delayed action oscillator for ENSO. J Atmos Sci 45:3283-3287

Sun F, Yu J-Y (2009) A 10-15-year modulation cycle of ENSO intensity. J Climate 22:1718-1735

Trenberth KE, Stepaniak DP (2001) Indices of El Niño evolution. J Climate 14:1697-1701

Yu, J.-Y. and S. T. Kim (2010) Relationships between extratropical sea level pressure variations and the Central-Pacific and EasternPacific types of El Niño. J Climate (submitted).

Yu J-Y, Sun F, Kao H-Y (2009) Contributions of Indian Ocean and monsoon biases to the excessive biennial ENSO in CCSM3. J Climate 22:1850-1858

Yu J-Y, Kao H-Y, Lee T (2010) Subtropics-related interannual sea surface temperature variability in the equatorial central Pacific. J Climate 23:2869-2884 